\title{
Organizational-and-technological solutions to optimize the quality control of building materials
}

\author{
Dmitry Topchiy",Vitaly Chernigov, Irina Grunina, and Ekaterina Kochurina \\ Moscow State University of Civil Engineering, 129377, Moscow, Russia
}

\begin{abstract}
The paper presents the results of the analysis of foreign and Russian experience in the field of research and development of new methods for the accelerated determination of frost resistance of concrete, as well as a description of the experimental method for determining frost resistance by exposing the tested samples to extremely low temperatures. The development of the building materials market, the improvement of construction and installation work technologies require the use of modern high-tech technologies and means, including in the implementation of construction control at unique construction facilities. Currently used regulatory documents of the Russian Federation and standards of foreign countries imply large time costs and high labor intensity. Foreign and domestic scientific research describes other methods of testing using expensive equipment, a large amount of mathematical calculations and mathematical modeling. Reducing the time interval for testing will slightly change. The developed experimental method takes into account the requirements of the regulatory documentation in force on the territory of the Russian Federation, and implies cyclic freezing of samples saturated in a $5 \%$ aqueous solution of sodium chloride at extremely low temperatures achieved by using liquid nitrogen. Based on the results of parallel tests in accordance with the requirements of regulatory documents and in accordance with the developed experimental method, a positive convergence of the results was obtained. A significant decrease in the time of testing to determine the frost resistance of concrete was recorded, which allows concluding that it is advisable to use this experimental method, especially if it is necessary to quickly control the quality of concrete at unique construction facilities.
\end{abstract}

\section{Introduction}

The dynamics of the development of production and the market of building materials, the modernization of the technology for construction and installation works, the means of large and small mechanization stimulate the growth in the number of objects that are classified as unique. Implementation of construction control at unique construction facilities requires the

\footnotetext{
${ }^{*}$ Corresponding author: vitaha-rock@mail.ru
} 
use of modern, scientifically grounded technological solutions and tools to meet the need forreducing risks, obtaining work results without significant time costs caused, first of all, by a long period of testing building materials and structures.

According to article 48.1 of the Urban Planning Code of the Russian Federation of December 29, 2004 No. 190-FZ (as amended on 27.06.19), the unique capital construction facilities include objects, the design of which includes at least one of the following parameters [3-5]:

1) height over $100 \mathrm{~m}$;

2) spans over $100 \mathrm{~m}$;

3) the presence of a console over $20 \mathrm{~m}$;

4) deepening of the underground part below the planning level of the earth formore than $15 \mathrm{~m}$.

The implementation of the above parameters implies technical and technological difficulties, which makes it necessary to carry out quality control of the materials, products and structures used with special attention. Even minor violations of the production technology at unique construction sites are associated with a high level of risk during construction and installation work and further operation of the building.

Modern organizational and technological solutions for the implementation of construction control at unique construction facilities are based on standards, which, in turn, do not take into account the trends to reduce risks and minimize the time spent on performing various types of operations to confirm the quality indicators of materials and structures. One of these indicators is the frost resistance of concrete. The time interval required to determine the grade for the frost resistance of concrete of monolithic structures can have a significant impact on the timing of construction and installation works, which is unacceptable if there is any doubt about the quality of the concrete mixture supplied to the construction site. As a result, there is a possibility of downtime and significant delays in the commissioning of the facility.

Frost resistance is one of the most important indicators of concrete quality. According to the Russian State Standard GOST 10060-2012 "Concrete. Methods for determining frost resistance (with Amendments)" is defined as the ability of concrete in a water-saturated state or saturated with solution of salts to withstand repeated freezing and thawing without external signs of destruction, decrease in strength, change in weight and other technical characteristics [1]. The indicator depends on the type of concrete, its macro- and microstructure, components used for the manufacture of a concrete mixture, and on the environmental conditions in which the concrete structure is used. In order to obtain the concrete frost resistance grade set by the project or technical task, as a rule, various airentraining admixtures are used. The use of this type of chemical additives allows creating a system of closed pores in the concrete body by generating ultra-stable, small air systems of bubbles located close to each other in the concrete structure. According to the international classification, the optimal air content in concrete structures should be in the range from 4 to $6 \%$.

Concretes of high frost resistance (grades more than F300) are used in construction in harsh climatic conditions with deep freezing of the soil and for especially critical structures with increased levels of stability and importance. The main danger in this case is not the operation of the building in an area with critically low temperatures, but the constantly repeating cycles of freezing and thawing of water in the concrete body, which causes internal stresses, the appearance of defects and, as a result, the loss of performance of the structure.

This paper discusses possible methods for optimizing tests to determine the grade of concrete for frost resistance, taking into account the requirements of the current regulatory 
and technical documents and modern solutions for organizing construction control during the construction of unique buildings and structures.

\section{Materials and methods}

The existing normative and technical documents providing the construction control do not fully take into account the features that arise during the construction of unique buildings. At the same time, technological progress in the field of equipment development and the improvement of testing and measurement methods ensure the possibility of full operational quality control of materials and work during construction.

In accordance with the requirements of GOST 25192-2012 "Concrete. Classification and general technical requirements" and other regulatory and technical documents, the indicator is classified by the grade of concrete for frost resistance. The grade is assigned based on the results of tests that imply cyclic freezing and thawing of samples saturated with water or an aqueous solution of salts, followed by determining their strength characteristics and the presence of structural defects [2].

The regulatory framework of the Russian Federation provides for several methods for determining the frost resistance of concrete. In accordance with GOST 10060-2012 "Concrete. Methods for determining frost resistance (with amendments)", they are classified according to the time of implementation into basic and accelerated ones. Basic methods are based on cyclic freezing of saturated water or $5 \%$ aqueous sodium chloride solution to a temperature of $-18( \pm 2)^{\circ} \mathrm{C}$, followed by thawing the samples in water or salt solution at a temperature of $+20( \pm 2)^{\circ} \mathrm{C}$. Accelerated methods also imply cyclic freezing of samples saturated with water or a $5 \%$ aqueous solution of sodium chloride to critical temperatures of $-50( \pm 2)^{\circ} \mathrm{C}$ and thawing of samples in a solution of sodium chloride at a temperature of $+20( \pm 2)^{\circ} \mathrm{C}[1]$.

From the system of international foreign standards, the ASTM C666, ASTM C671 and ASTM C1262-95 standards developed in the USA can single out. These standards provide three methods for testing frost resistance: "Standard method for determining the resistance of concrete to accelerated freezing and thawing", "Standard method for critical swelling of concrete samples during freezing" and "Evaluation method for testing the durability of concrete blocks and mortars during alternating freezing and thawing”. Further, the analysis of the methods from the above regulatory documents is carried out.

ASTM C666 USA "Standard method for determining concrete resistance to accelerated freezing and thawing" provides two methods for accelerated determination of frost resistance in a laboratory, similar to the requirements of Russian regulations. Freeze/thaw cycle temperature is down to $-17.8-4.4^{\circ} \mathrm{C}\left(0 \sim 40^{\circ} \mathrm{F}\right)$, one cycle lasts 2 to 5 hours. When freezing according to method $\mathrm{A}$, the samples are pre-saturated with water. According to method B, freezing occurs in air. For thawing, the samples are placed in water. The thawing time is at least $20-25 \%$ of the total duration of one cycle. When testing using this method, 300 cycles of freezing - thawing are repeated or until the value of the dynamic modulus of elasticity is reduced by $60 \%$ of the initial value. Then the coefficient of durability is calculated [6].

According to ASTM C671 "Standard method of critical swelling of concrete samples during freezing", the mode of slow freezing and fast thawing is set; the freeze-thaw cycle is tested once every two weeks; the freezing temperature of the samples is $-9.4{ }^{\circ} \mathrm{C}$, the thawing temperature is $+1.7^{\circ} \mathrm{C}$. During the test, the linear swelling of the concrete is measured until the critical swell or the required number of cycles is reached. If the value of linear swelling exceeds $0.02 \%$, then it speaks of low frost resistance of concrete. Although this test method is closer to the actual freeze-thaw mode, it is not often used due to its high labor intensity and significant time costs [7]. 
ASTM C1262-95 "Evaluation method for testing the durability of concrete blocks and mortars during alternating freezing and thawing" is a method for assessing the durability of concrete based on measuring the weight loss of concrete after freezing and thawing. According to this method, the sample freezing temperature is $-15 \pm 2.8^{\circ} \mathrm{C}$, the exposure time is 4 5 hours; thawing occurs at a temperature of $18.3 \sim 23.9^{\circ} \mathrm{C}$ and lasts from 2.5 to 72 hours. The results obtained are expressed in fractions of mass from the initial weight of concrete in a dry state every 8-12 cycles. The higher the weight loss of concrete, the worse its frost resistance [8].

The regulatory documents considered above describe methods for determining frost resistance similar to those presented in Russian standards and also imply large time costs for sample preparation and testing.

The experience of researchers at the Brno University of Technology (Czech Republic) is based on the application of the acoustic emission method to determine the frost resistance of concrete in order to record microstructural changes. The acoustic emission method can be attributed to non-standard methods of non-destructive testing. The equipment makes it possible to monitor structural changes during routine measurements of concrete frost resistance. In this case, the acoustic emission method detects only active defects in the structure under study. Thus, in the presence of the dynamics of crack development, some acoustic waves propagate from the location of the crack, i.e. from the source of acoustic emission. The method does not detect geometry defects - passive defects. Non-destructive methods such as ultrasonic nonlinear spectroscopy, impact response, etc. are used to confirm microstructural changes. The paper considers an experiment using acoustice mission [9].

Acoustic emission is a term for noise emitted by materials and structures when they are subjected to stress. This radiation is caused by the rapid release of energy within the material due to such events as cracking and subsequent stretching due to an applied stress. The acoustic emission method allows tracking changes in the behavior of materials over a long time and without moving one of its components, i.e. sensors. This makes the method completely unique along with the ability to detect the propagation of cracks that occur not only on the surface, but also deep inside the material. The use of the acoustic emission method in frost resistance tests can help to track structural micro-changes in this phenomenon. It is assumed that structural changes will follow changes in temperature [9].

A shock-echo-signal method based on monitoring surface movement as a result of short-term mechanical action is also proposed. One of the key features of the method is the transformation of the surface motion waveform recorded in the time domain into the frequency domain. On impact, vibration modes arise, and the frequency of these modes is related to the geometry of the test object.

Scientists from Japan and China propose to determine the frost resistance of concrete in terms of air permeability. In this study, a method is proposed for determining damage to the structure of concrete in the early stages as a result of cyclic freezing and thawing by measuring the parameter of air permeability. To confirm the theory, two stages of testing were carried out. At the first stage, the depth of freezing of concrete was studied, at the second - the freezing time. As a result, it was confirmed that the early damage to concrete due to freezing can be determined by measuring the air permeability of the flow depending on the depth of freezing and the beginning of freezing. Also, by comparing the test results of concrete and mortar samples, a criterion was proposed for determining damage in the early stages of freezing by measuring the air permeability of the flow. The proposed method of air flow permeability can also be used to detect changes in the integrity of concrete in finished structures directly at the construction site, and the effect of early freezing on the durability of concrete is also studied [10]. 
In the Russian Federation, a patent was registered for a method for determining the frost resistance of concrete by loading a prismatic specimen with a compressive load at its ends, determining the models of concrete deformations and calculating frost resistance according to a unique formula that differs in determining the modulus of concrete deformation at a loading level equal to the short-term strength limit and the initial modulus of elasticity. The formula has a direct dependence on the frost resistance of concrete at a freezing temperature of up to $-50^{\circ} \mathrm{C}$, the above-mentioned deformation and elasticity moduli, and empirical coefficients [10].

At the Peter the Great St. Petersburg Polytechnic University, a comparison of two methods for the accelerated determination of frost resistance was carried out. The first is the energy method based on measuring the energy of destruction of concrete. In this case, the frost resistance grade is defined as the number of freeze-thaw cycles, which consume the energy dissipated throughout the sample volume during the freeze-thaw process within the limits of permissible absolute changes in the energy dispersed in volume unit of sample. The second is the method of permanent deformations based on the measurement of permanent deformations after each freeze-thaw cycle [10].

Both methods are based on the principles of deformation of an anisotropic solid medium. In the course of the work, a relationship between the energy released by the sample during one thermal cycle and the energy released during the complete destruction of the sample was revealed. The frost resistance of a sample is defined as the ratio of the energy released during the complete destruction of the sample to the energy released by the sample in one thermal cycle, and the frost resistance of the material is determined as the arithmetic mean for all samples. The proposed method is distinguished by high efficiency, low labor intensity and a wide arsenal of technical means.

To optimize and improve the methodology for determining frost resistance, it is necessary to solve the following tasks: shortening the measurement time, which will allow conducting operational control, and the use of widely available equipment and materials.

To address this issue, taking into account the requirements of GOST 10060-2012 "Concrete. Methods for determining frost resistance (with amendments)", an experimental method was developed for the accelerated determination of frost resistance under the influence of extremely low temperatures achieved by using liquid nitrogen.

The tests were carried out using concrete samples used for road and airfield surfaces according to the third accelerated method. In order to obtain comparative results, parallel tests were carried out according to the experimental method and in accordance with the requirements of GOST 10060-2012 "Concrete. Methods for determining frost resistance (with amendments)".

Description of the research object:

Samples are cubes selected from structures, $10.0 \times 10.0 \times 10.0 \mathrm{~cm}$, made of concrete mix of project class B35 and frost resistance grade F200.

To confirm the frost resistance grade when conducting tests by the accelerated method in accordance with the requirements of Table 4 for the third accelerated method of GOST 10060-2012 "Concrete. Methods for determining frost resistance (with Amendments)", the number of cycles to confirm frost resistance of the F200 grade were 20 without loss in strength of more than $10 \%$ in comparison with control samples, weight reduction of no more than $2 \%$ and without external damage (cracks, chips and surface peeling). Test condition sares how in table 1 .

Table 1. Test conditions

\begin{tabular}{lll}
\hline Method and & Test conditions & Concrete type
\end{tabular}




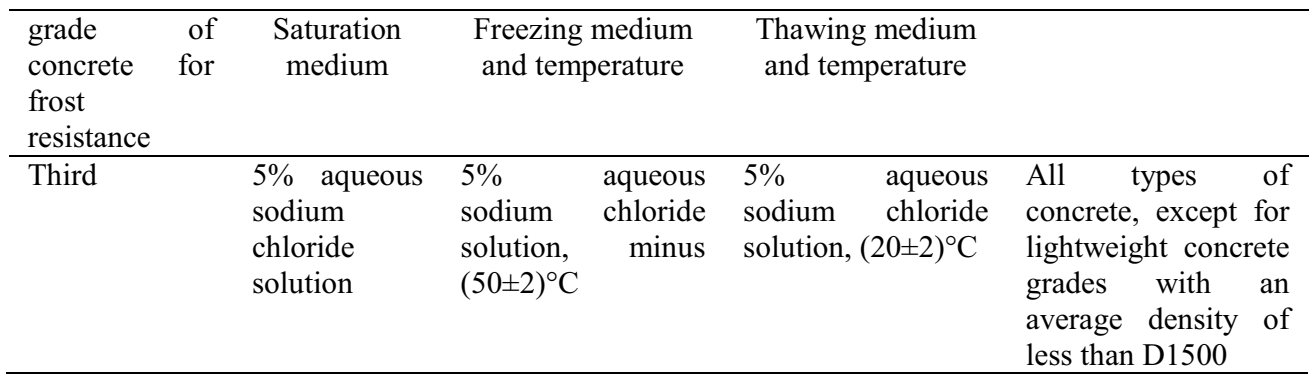

The tests were carried out in the following order:

1) Control samples of concrete before testing for strength, and the main samples before freezing are saturated with a $5 \%$ aqueous solution of sodium chloride at a temperature of $(20 \pm 2)^{\circ} \mathrm{C}$. To saturate, the samples are immersed in water or sodium chloride solution at $1 / 3$ of their height for 24 hours, then the level of water or solution is raised to $2 / 3$ of the height of the samples and kept in this state for another 24 hours, after which the samples are completely immersed in water or solution for $48 \mathrm{~h}$ so that the liquid level is at least $20 \mathrm{~mm}$ above the upper edge of the samples.

2) Control samples saturated with water are removed from the water, wiped with a moist rag and tested for compression in accordance with GOST 10180.

3) A hole is drilled in the main samples, and a thermocouple is placed in its center. The hole is insulated from any external influences using machine oil, foam, and sealant. The thermocouple layout is shown in figure 1.

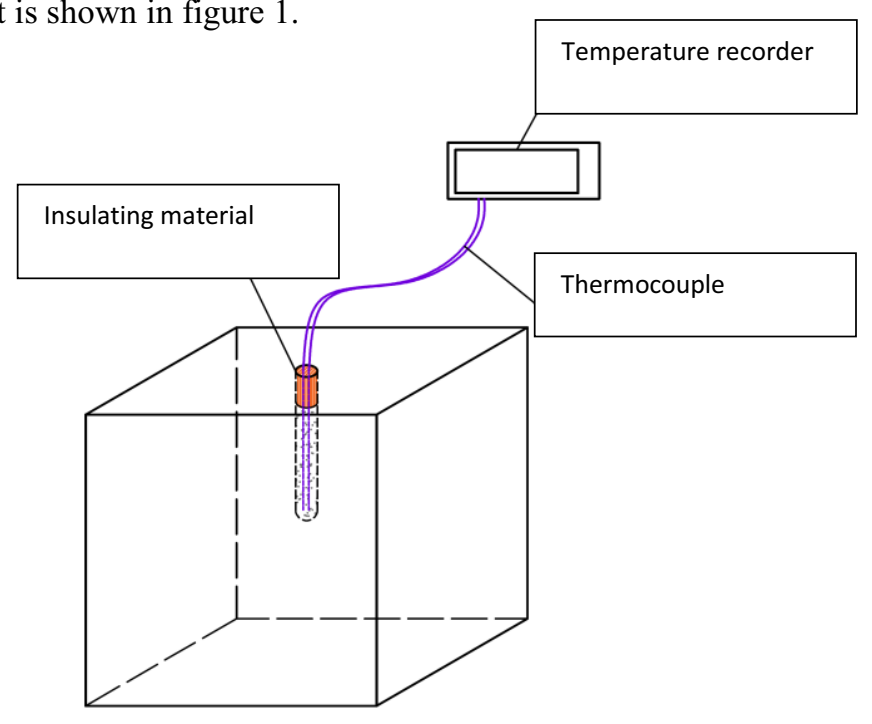

Fig. 1. Layout of the thermocouple inside the sample

4) The main samples are placed in top-closed containers filled with a 5\% aqueous sodium chloride solution. The temperature is reduced by adding liquid nitrogen to the tanks. The temperature of the sample is lowered to minus $(50 \pm 2)^{\circ} \mathrm{C}$ in the center of the sample. The temperature is recorded by a thermocouple and a Terem-3.2 meter-recorder of thermal processes.

The Terem-3.2 programmable multichannel meter-recorder of thermal processes is designed to control, record in memory and display information coming from temperature sensors (ChC- or ChA-thermocouples, DS1820 digital sensors, DS1820MK upgraded 
digital sensors) and/or combined temperature-humidity sensors. The device is applicable for the control of technological processes in various industries, in particular, during accelerated hardening of monolithic and prefabricated reinforced concrete in construction.

The basis of the recorder is a microprocessor-based central device, to which one or several adapters for communication with sensors are connected via a four-wire communication line. The length of the communication line and the required types of adapters depend on the specific object on which the recorder is installed. Adapters are made individually and can serve sensors of one or different types. To reduce the influence of interference, adapters are located near the sensors.

The duration of the freezing cycle is adjusted directly during the tests, the average value based on the results of the test series is 5-7 minutes, and the temperature difference is recorded in real time.

Empirically, using thermographic research methods, it was found that the thermocouple wire and the insulated channel are not a cold bridge, there is no heat transfer directly through the thermocouple wire. Figure 2 shows the temperature distribution inside the sample at the time of testing.

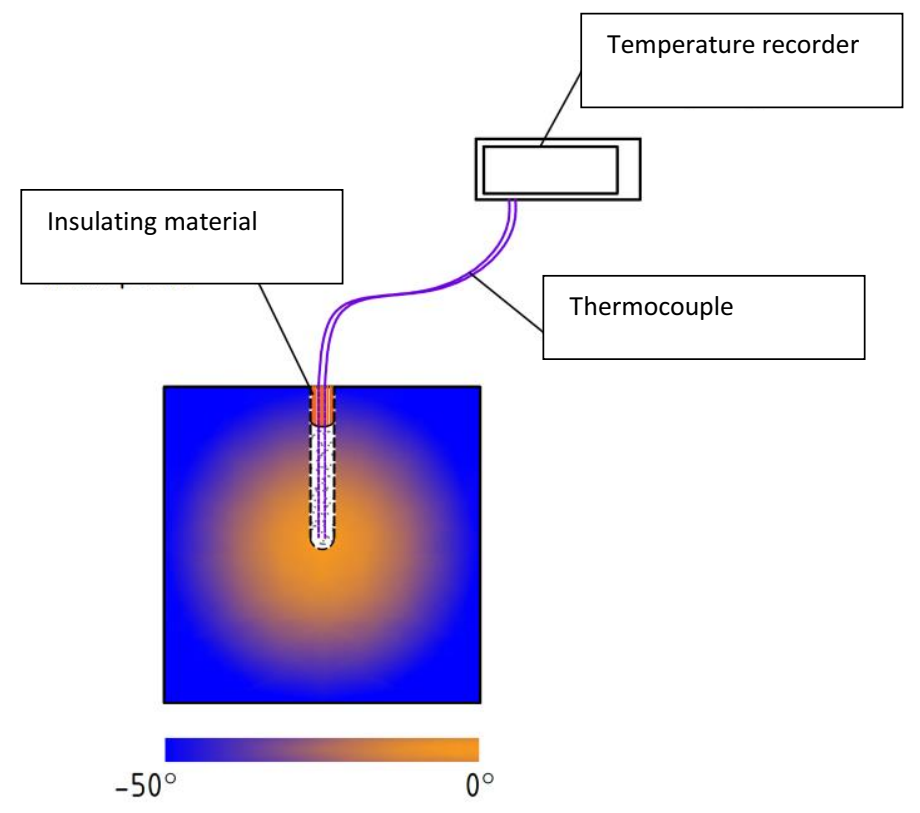

Fig.2. Distribution of the temperature gradient in the sample

5) The samples are thawed in a $5 \%$ aqueous solution of sodium chloride with a temperature of $(20 \pm 2)^{\circ} \mathrm{C}$ until the temperature of $(20 \pm 2)^{\circ} \mathrm{C}$ is reachedin the center of the sample.The temperature is reached in 20-25 minutes. The temperature is also recorded with a thermocouple and Terem-3.2meter-recorder of thermal processes. The cycle is considered complete when the temperature in the center of the sample reaches $(10 \pm 2)^{\circ} \mathrm{C}$.

6) After a specified number of cycles, the main specimens are examined. The material separating from the sample is removed with a hard nylon brush. The samples are wiped with a moist rag, weighed and tested for compression. The test is repeated.

To obtain accurate results, the samples were examined for external defects and damage after each cycle, tests to determine the strength characteristics are conducted after 5 cycles. Figure 3 shows a sample after 20 cycles of alternating freezing and thawing. Chipped ribs, peeling of the surface and weight loss of more than $2 \%$ are observed. The results of determining the strength characteristics (Table 2) show a loss in strength in comparison 
with the control samples of more than $10 \%$. In this series of samples, the required frost resistance grade has not been confirmed.

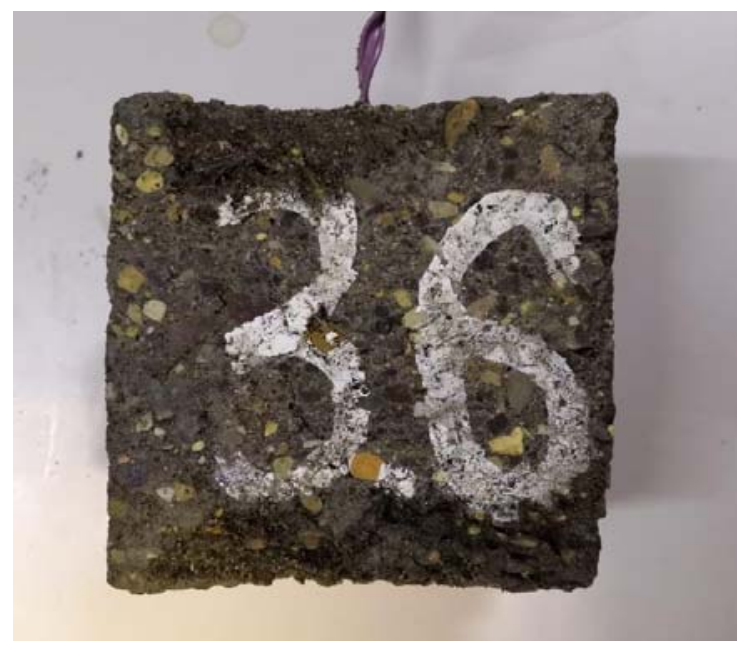

Fig. 3. Main sample after 20 freeze-thaw cycles

Concrete grade for frost resistance is taken according to table 4 for the third accelerated method of GOST 10060-2012 "Concrete. Methods for determining frost resistance (with amendments)", taking into account the number of cycles at which the loss of strength in comparison with the control samples does not exceed $10 \%$, the decrease in the mass of the samples does not exceed $2 \%$, there are no cracks, chips and flaking of the ribs.

According to the requirements of table 4 for the third accelerated method of GOST 10060-2012 "Concrete. Methods for determining frost resistance (with Amendments)", the number of cycles to confirm frost resistance of the F200 grade is 20 . The time spent on the full cycle of testing using liquid nitrogen was 106 hours, of which 96 were spent on preparing samples for testing and 10 hours on carrying out 20 cycles. In parallel, tests were carried out to determine frost resistance strictly according to the requirements of GOST. The time spent on testing is 236 hours, of which 96 were spent on sample preparation and 140 hours on carrying out 20 cycles.

\section{Results and discussion}

Nowadays, there are requirements established by the regulatory and technical framework for construction control, including for control of the grade for frost resistance of concrete.

The method described in GOST 10060-2012 "Concrete. Methods for determining frost resistance (with amendments)" is proven and reliable, provided by the regulatory and technical base. The main disadvantage is the significant amount of time required for sample preparation and testing, which makes it impossible to conduct on-line control.

The method proposed by the ASTM standards in the USA is similar to Russian regulatory documents in most of the points, requirements and technology for testing, and also implies a large time costs and labor intensity of work.

The analysis of the above studies of foreign and Russian colleagues allows concluding that it is possible to apply these methods in practice in view of the accuracy proved by the results and the presence of the following problems that need to be solved: labor intensity of work, long testing time, the presence of complex and expensive equipment, a large amount 
of preparatory stages, the need for complex mathematical calculations and the use of mathematical modeling.

According to the results of the experiment using the proposed method, a positive convergence of the results (Table 2) and a significant reduction in the time of the experiment due to a reduction in the stage of cyclic freezing and thawing of samples were established.

Table 2. Comparative table of test results.

\begin{tabular}{|c|c|c|c|c|c|c|c|c|c|}
\hline No. & 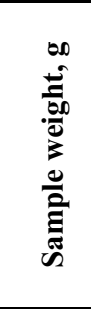 & 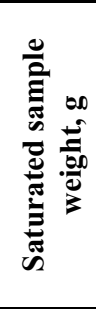 & 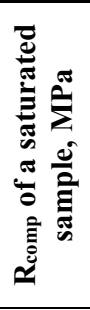 & 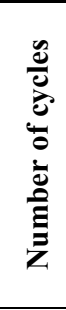 & 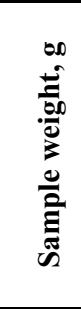 & 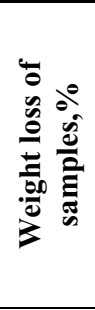 & 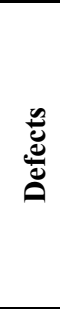 & 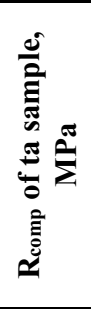 & 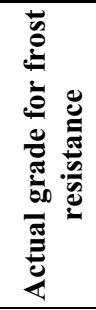 \\
\hline \multicolumn{10}{|c|}{ Testing in accordance with the requirements of GOST 10060-2012 } \\
\hline 1 & 2263 & 2304 & 48.6 & - & - & - & - & - & \multirow{15}{*}{ F200 } \\
\hline 2 & 2227 & 2266 & 45.9 & - & - & - & - & - & \\
\hline 3 & 2233 & 2272 & 46.7 & - & - & - & - & - & \\
\hline 4 & 2335 & 2373 & - & 5 & 2354 & 0.80 & no & 45.5 & \\
\hline 5 & 2325 & 2366 & - & 5 & 2349 & 0.72 & no & 47.4 & \\
\hline 6 & 2290 & 2326 & - & 5 & 2312 & 0.60 & no & 46.9 & \\
\hline 7 & 2282 & 2317 & - & 10 & 2298 & 0.82 & no & 44.9 & \\
\hline 8 & 2289 & 2342 & - & 10 & 2331 & 0.47 & no & 45.1 & \\
\hline 9 & 2259 & 2309 & - & 10 & 2296 & 0.56 & no & 46.8 & \\
\hline 10 & 2300 & 2350 & - & 15 & 2328 & 0.94 & no & 48.7 & \\
\hline 11 & 2219 & 2274 & - & 15 & 2269 & 0.22 & no & 46.9 & \\
\hline 12 & 2283 & 2333 & - & 15 & 2321 & 0.51 & no & 45.1 & \\
\hline 13 & 2313 & 2360 & - & 20 & 2330 & 1.27 & no & 44.8 & \\
\hline 14 & 2211 & 2265 & - & 20 & 2231 & 1.50 & no & 43.5 & \\
\hline 15 & 2398 & 2420 & - & 20 & 2387 & 1.36 & no & 42.9 & \\
\hline \multicolumn{10}{|c|}{ Testing according to the experimental method } \\
\hline 1 & 2321 & 2358 & 46.6 & - & - & - & - & - & \multirow{8}{*}{ F200 } \\
\hline 2 & 2329 & 2377 & 45.8 & - & - & - & - & - & \\
\hline 3 & 2345 & 2387 & 44.5 & - & - & - & - & - & \\
\hline 4 & 2339 & 2385 & - & 5 & 2375 & 0.42 & no & 47.1 & \\
\hline 5 & 2346 & 2399 & - & 5 & 2387 & 0.50 & no & 46.7 & \\
\hline 6 & 2331 & 2376 & - & 5 & 2369 & 0.29 & no & 48.2 & \\
\hline 7 & 2327 & 2370 & - & 10 & 2359 & 0.46 & no & 46.2 & \\
\hline 8 & 2332 & 2378 & - & 10 & 2355 & 0.97 & no & 45.4 & \\
\hline
\end{tabular}




\begin{tabular}{|c|c|c|c|c|c|c|c|c|}
\hline 9 & 2348 & 2389 & - & 10 & 2375 & 0.59 & no & 47.9 \\
\hline 10 & 2324 & 2362 & - & 15 & 2335 & 1.14 & no & 46.0 \\
\hline 11 & 2327 & 2378 & - & 15 & 2361 & 0.71 & no & 45.5 \\
\hline 12 & 2351 & 2402 & - & 15 & 2379 & 0.96 & no & 44.9 \\
\hline 13 & 2321 & 2364 & - & 20 & 2324 & 1.69 & no & 44.7 \\
\hline 14 & 2327 & 2378 & - & 20 & 2337 & 1.72 & no & 45.1 \\
\hline 15 & 2347 & 2385 & - & 20 & 2342 & 1.80 & no & 45.5 \\
\hline
\end{tabular}

Based on the data in Table 2, it can be concluded that according to the test results in accordance with the requirements of GOST and according to the experimental method, the design grade for frost resistance was confirmed. Despite the use of critical temperatures for freezing at the shortest possible time interval, early destruction of samples does not occur due to a sharp temperature drop in the center and along the edges of the sample. Temperature stresses leading to the appearance of defects in the first freezing cycles and contributing to the incorrect determination of the actual grade of concrete for frost resistance do not arise in the sample.

\section{Conclusions}

Summarizing all of the above, it can be concluded that today Russian and foreign regulatory and technical documents in the field of construction control do not regulate testing for accelerated determination of concrete frost resistance.

An analysis of experimental methods presented in a large number of scientific works, as well as an increase in the volume of construction, including unique buildings and facilities, whose structures are often subject to increased requirements for frost resistance, proves the relevance of this problem.

Based on the data obtained, there is a positive convergence with the test results according to the procedures regulated by the regulatory and technical documentation, as well as a significant reduction in the measurement time, which proves the effectiveness and can be applied in practice if it is necessary to control the quality of construction and installation works, including erection of unique buildings and facilities.

\section{References}

1. L. Pazdera, Topolar. Application of the acoustic emission method for assessing the frost resistance of concrete, ussian Journal of Nondestructive Testing 2, 87-92 (2014)

2. Hyeonggil Choia, Wenyan Zhangb, Yukio Hamaa, Method for determining early-age frost damage of concrete by using air-permeability index and influence of early-age frost damage on concrete durability, Construction and Building Materials 153, 630-639 (2017).

3. G.V. Nesvetaev, Patent for invention No. RU 2059243 C1. Application number 94005775/33. Date of publication 27.04.1996.

4. O.N. Pertseva, A.D. Selezneva, D.A. Pulnikova, Verification of the reliability of accelerated methods for determining the frost resistance of concrete, Systems. Methods. Technologies 1(37), 85-90 (2018).

5. A. Yurgaytis et al., E3S Web of Conferences 164, 02023 (2020) 
5. A. Bolotova and G. Treskina, Collection of works of an international research conference (Moscow, 2015)

6. A. Bolotova, Science Review 18, 186 (2016)

7. A. Lapidus and I. Abramov, E3S Web of Conferences 33, 03066 (2018)

8. D. Topchiy et al., IJCIET 1, 985-993 (2018)

9. D. Topchiy and E. Kochurina, System technologies 1 (26), 107 (2018) 